\title{
Current Status and Scope of Lymph Node Micrometastasis in Gastric Cancer
}

\author{
Chang Min Lee ${ }^{1}$, Sung-Soo Park ${ }^{1,2}$, and Jong-Han Kim ${ }^{1,2}$ \\ ${ }^{1}$ Department of Gastroenterologic Surgery, Korea University Medical Center, \\ ${ }^{2}$ Department of Surgery, Korea University College of Medicine, Seoul, Korea
}

Recently, lymph node micrometastasis has been evaluated for its prognostic value in gastric cancer. Lymph node micrometastasis cannot be detected via a usual pathologic examination, but it can be detected by using some other techniques including immunohistochemistry and reverse transcription-polymerase chain reaction assay. With the development of such diagnostic techniques, the detection rate of lymph node micrometastasis is constantly increasing. Although the prognostic value of lymph node micrometastasis remains debatable, its clinical impact is apparently remarkable in both early and advanced gastric cancer. At present, studies on the prognostic value of lymph node micrometastasis are evolving to overcome its current limitations and extend the scope of its application.

Key Words: Lymph nodes; Micrometastasis; Stomach neoplasms

\section{Introduction}

In gastric cancer, lymph node metastasis is known as a significant prognostic factor. ${ }^{1-3}$ For this reason, radical lymph node dissection has been included in curative surgery for patients with gastric cancer. ${ }^{4}$ However, a node-negative state (pNO) confirmed by conventional $\mathrm{H} \& \mathrm{E}$ staining does not guarantee long-term survival without recurrence. ${ }^{5-9}$ Some researchers suggested that this phenomenon could be caused by the existence of micrometastasis in regional lymph nodes. ${ }^{5-7,10}$ Lymph node micrometastasis is not detected via a conventional pathologic examination, in which the $\mathrm{H} \& \mathrm{E}$ staining method is employed. Recently, immunohistochemical staining techniques have been applied for detecting micrometastasis in the lymph nodes. ${ }^{5,10-15}$ In addition, the serial sectioning

Correspondence to: Jong-Han Kim

Department of Gastroenterologic Surgery, Korea University Ansan Hospital, 123 Jeokgeum-ro, Danwon-gu, Ansan 425-707, Korea

Tel: +82-31-412-4936, Fax: +82-31-413-4829

E-mail: ppongttai@gmail.com

Received December 14, 2014

Revised January 12, 2015

Accepted January 13, 2015 method $^{16}$ and reverse transcription-polymerase chain reaction (RTPCR) assay ${ }^{17}$ are other strategies for detecting micrometastasis. All of these newly developed tools have enabled researchers to investigate the clinical significance of micrometastasis. In this article, we will review the current status and scope of lymph node micrometastasis in gastric cancer.

\section{Main Subjects}

\section{Definition of lymph node micrometastasis}

Currently, micrometastatic foci in lymph nodes are classified as micrometastasis and isolated tumor cells (ITC) according to their size. ${ }^{18}$ First, micrometastasis is defined as tumor cell clusters between $0.2 \mathrm{~mm}$ and $2.0 \mathrm{~mm}$ in the greatest dimension, whereas ITC are defined as single tumor cells or small clusters of tumor cells less than $0.2 \mathrm{~mm}$ in size. Moreover, according to the 7th TNM classification by the International Union Against Cancer, ${ }^{19}$ lymph node micrometastasis should be reflected in the node staging of the disease, whereas ITC do not affect the stage. However, micrometastasis is not always regarded as pN1. Unless lymph node positivity is diagnosed by morphological methods, such as H\&E staining 


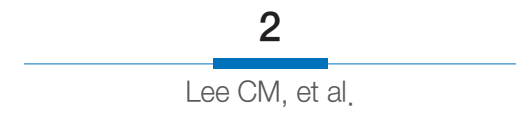

or immunohistochemistry (IHC), it is usually regarded as pNO. For instance, even if micrometastasis is detected by RT-PCR, its pathologic $\mathrm{N}$ stage is determined as $\mathrm{pNO}(\mathrm{mol}+)$.

\section{Diagnostic tools for lymph node micrometastasis}

As described above, both micrometastasis and ITC cannot be detected via a typical pathologic examination, such as H\&E staining. Therefore, many studies have been performed to establish effective methods for detecting micrometastasis. ${ }^{20}$ As a result, some other diagnostic techniques have been introduced to detect lymph node micrometastasis in patients with gastric cancer (Table 1). ${ }^{5,10,12-15,17,21-30}$

\section{1) Immunohistochemical staining}

Currently, IHC is a widely accepted technique for detecting lymph node micrometastasis in gastric cancer. ${ }^{10,11,25}$ When micrometastasis is detected by IHC, epithelial markers such as cytokeratin are used. ${ }^{31}$ Cytokeratin is a fundamental element comprising the cellular structure of normal or malignant epithelial cells. In the IHC procedure, the slices of lymph nodes are prepared with a monoclonal antibody reactive to human cytokeratin. ${ }^{15,24}$ In previous studies that applied IHC, cytokeratin (CK) AE1/AE3 and CAM 5.2 have been employed as the monoclonal antibodies. ${ }^{16,17,25,31-35}$ Using these monoclonal antibodies, even a single tumor cell can be detected. Micrometastatic foci are stained brown by IHC using a CAM 5.2 antibody (Fig. 1).

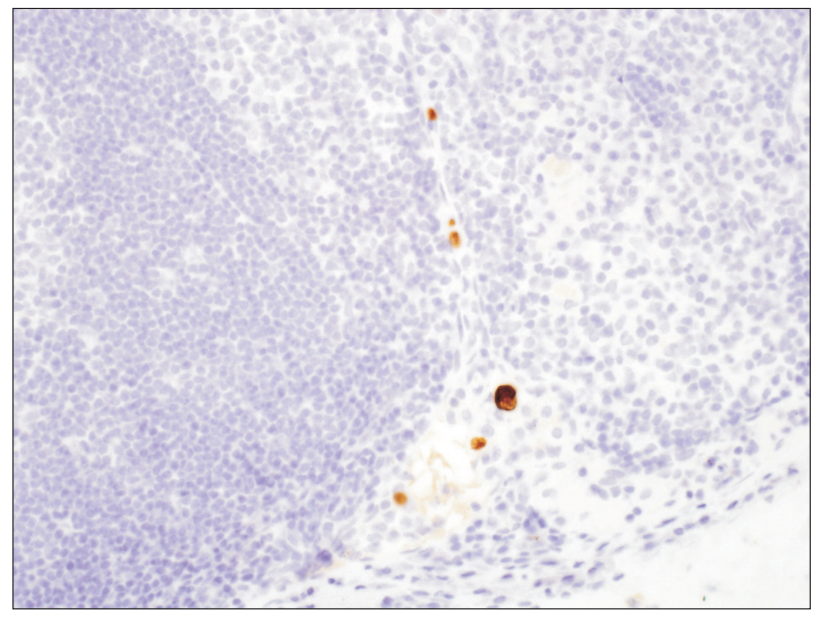

Fig. 1. Microscopic view of micrometastatic foci (immunocytochemistry stain with antibody CAM 5.2, ×400). Micrometastatic foci were stained with brownish color by immunohistochemical staining.

Table 1. Previous studies that assessed the detection of lymph node micrometastasis in patients with gastric cancer

\begin{tabular}{|c|c|c|c|c|c|}
\hline Study & No. of patients & Pathologic results by $\mathrm{H} \& \mathrm{E}$ & Methods & Target markers & Incidence $(\%)^{\star}$ \\
\hline Maehara et al. ${ }^{5}(1996)$ & 34 & pT1N0 & $\mathrm{IHC}$ & CK (CAM 5.2) & 23.5 \\
\hline Kashimura et al. ${ }^{21}$ (1999) & 47 & pT1bN0 & $\mathrm{IHC}$ & CK (CAM 5.2) & 23.4 \\
\hline Harrison et al. ${ }^{22}(2000)$ & 25 & pT1-4N0 & $\mathrm{IHC}$ & CK (CAM 5.2) & 36.0 \\
\hline Cai et al. ${ }^{13}(2000)$ & 69 & pT1bN0 & IHC & CK (CAM 5.2) & 24.6 \\
\hline Okada et al. ${ }^{23}(2001)$ & 24 & pT1-4aN0 & RT-PCR & CEA, CK (20), MAGE 3 & 41.7 \\
\hline Nakajo et al..$^{24}(2001)$ & 67 & pT1-3N0 & IHC & CK (AE1/AE3) & 14.9 \\
\hline Matsumoto et al. ${ }^{17}$ (2002) & 50 & pT1-4N0 & RT-PCR & CEA & 28.0 \\
\hline Lee et al. ${ }^{14}(2002)$ & 41 & pT1N0 & $\mathrm{IHC}$ & CK (AE1/AE3) & 24.4 \\
\hline Yasuda et al. ${ }^{15}(2002)$ & 64 & pT2-4aN0 & $\mathrm{IHC}$ & CK (CAM 5.2) & 31.3 \\
\hline Choi et al. ${ }^{12}(2002)$ & 88 & pT1bNo & $\mathrm{IHC}$ & CK $(35 \beta H 11)$ & 31.8 \\
\hline Morgagni et al. ${ }^{25}$ (2003) & 300 & pT1N0 & $\mathrm{IHC}$ & CK (MNF 116) & 10.0 \\
\hline Arigami et al. ${ }^{26}(2005)$ & 80 & pT1-3N0 & RT-PCR & CEA & 31.3 \\
\hline Sonoda et al. ${ }^{27}$ (2006) & 33 & pT1N0 & RT-PCR & MUC 2, TEF 1 & 33.3 \\
\hline Wu et al. ${ }^{28}(2007)$ & 10 & $\mathrm{pN} 0$ & RT-PCR & CK (20) & 20.0 \\
\hline Ishii et al. ${ }^{29}(2008)$ & 35 & pT1b-2N0 & IHC & CK (O.N.352) & 11.0 \\
\hline Cao et al. ${ }^{30}(2011)$ & 160 & pT1N0 & IHC & $\mathrm{CK}(\mathrm{AE} 1 / \mathrm{AE} 3)$ & 21.3 \\
\hline Ru et al..$^{10}(2012)$ & 45 & pT1-4N0 & IHC & CK (19), CD44v6 & 33.3 \\
\hline
\end{tabular}

$\mathrm{IHC}=$ immunohistochemistry; RT-PCR = reverse transcription-polymerase chain reaction; $\mathrm{CK}=$ cytokeratin; CEA = carcinoembryonic antigen; MAGE = melanoma-associated gene; MUC = mucin gene; TEF = transcription enhance factor. ${ }^{\star}$ This refers to the incidence of lymph node micrometastasis in patients who were diagnosed with pN0 via conventional pathologic examination. 
Together with the application of monoclonal antibodies, serial sectioning ${ }^{36}$ also contributed to improving the detection rate. Some researchers performed IHC only in representative slices of the lymph nodes. However, if micrometastasis exists in the remaining slices, it would not be detected. Concerning this issue, Isozaki et $\mathrm{all}^{36}$ reported the superiority of serial sectioning with IHC.

The incidence of lymph node micrometastasis is diverse according to the articles published on gastric cancer (Table 1). ${ }^{5,1,12-15,17,21-30}$ Cai et al. ${ }^{13}$ and Kashimura et al. ${ }^{21}$ reported that the incidence of lymph node micrometastasis was $25 \%$ and $23.4 \%$, respectively, in their articles on T1b gastric cancer. In addition, Kikuchi et al. ${ }^{37}$ published a study in which micrometastasis was detected in $43.2 \%$ of $\mathrm{T} 2$ cases. Meanwhile, Kim et al. ${ }^{38}$ reported that the incidence of lymph node micrometastasis was only $10 \%$ in pT1N0 gastric cancer. They assumed that the low incidence was caused by Tla (mucosa invasion) $\operatorname{cases}^{38}$; hence, it seems that the incidence of lymph node micrometastasis is proportional to the cancerous progression of disease in IHC. In other words, a high incidence of lymph node micrometastasis is found in cases involving relatively deep tumor invasion. ${ }^{5}$ However, as there is yet no reliable evidence, a systematic review or large-scale analysis is necessary to evaluate this issue.

\section{2) Reverse transcription-polymerase chain reaction assay}

Recently, developments of molecular biological techniques have influenced the detection of lymph node micrometastasis. The introduction of RT-PCR increased the detection rate of micrometastasis to a level higher than that achieved by $\mathrm{IHC} .^{17}$ The reason for its higher sensitivity was attributed to the amplification of gene transcripts associated with occult tumor cells. ${ }^{39-41}$ When micrometastasis is detected by RT-PCR, cytokeratin and carcinoembryonic antigen (CEA) are employed as target markers. ${ }^{17,23,26,28}$ CEA can be used as a target marker, since it is expressed in most cancer and normal gastrointestinal cells. ${ }^{42}$ According to the report by Arigami et al., ${ }^{26}$ RT-PCR assay identified lymph node micrometastasis in $31.3 \%$ of patients, whereas IHC detected lymph node micrometastasis in $11.3 \%$ of patients. Additionally, Kubota et al. ${ }^{43}$ also reported the higher sensitivity of duplex RT-PCR assay than IHC. For 304 lymph nodes with negativity according to the conventional histologic examination, the detection rates of duplex RT-PCR (using CEA and CK 20 as target markers) and IHC (using CK AE1/AE3 monoclonal antibodies as target markers) were $9.9 \%$ and $3.6 \%$, respectively.

\section{3) The advances of reverse transcription-polymerase chain reaction assay}

Despite the relatively high detection rate, there were some issues with RT-PCR assay for detecting lymph node micrometastasis. Ruud et al. ${ }^{44}$ noted that false-positive results might be caused by the contamination of a pseudogene. On the contrary, there could also be a possibility of false negativity because of the heterogeneous expression of a target marker. ${ }^{45}$ However, due to recent advances in this field, issues with accuracy concerning RT-PCR assay have been overcome. Moreover, technical advances have also improved the speed of analysis.

Recently, Yaguchi et al..$^{46}$ reported the application of one-step nucleic acid amplification (OSNA) for patients with gastric cancer, through which sentinel node navigation surgery (SNNS) has been considerably realized in this malignancy. As the intraoperative diagnosis of lymph node micrometastasis is mandatory in SNNS, rapidity as well as sensitivity is also required. OSNA targets only CK 19 expression, and it is based on real-time amplification and quantification of mRNA directly from the lysate of lymph nodes. ${ }^{47}$ Using this method, approximately 30 minutes are needed to investigate the presence of lymph node micrometastasis. ${ }^{46}$ In addition, its sensitivity and specificity were reported as $88.9 \%$ and $96.6 \%$, respectively. ${ }^{46}$

The Smart Cycler system (Cepheid, Sunnyvale, CA, USA) ${ }^{48}$ was suggested as another tool for rapid real-time RT-PCR assay. The advantages of this system are its rapid processing and ability to perform multiplex assays. Approximately 40 minutes are necessary to finish the analysis using the Smart Cycler system. Moreover, its sensitivity as well as the specificity could be improved by assessing both CEA and CK 19 mRNA expression. The Smart Cycler system is also expected to have an important role in the intraoperative detection of lymph node micrometastasis when SNNS is applied in gastric cancer.

\section{The prognostic value of lymph node microme- tastasis}

Regarding the prognostic significance of lymph node micrometastasis in gastric cancer, many studies have been performed in patients with node-negative tumors (Table 2). . $7,10,12-15,22,24,25,30,37,38,49,50$ In 1996, Maehara et al. ${ }^{5}$ reported the clinical significance of lymph node micrometastasis by investigating pT1N0 patients who died of recurrence. Of 34 patients with node-negative early gastric cancer (EGC), lymph node micrometastases were detected in eight $\mathrm{pa}^{-}$ tients who exhibited a poorer prognosis. Moreover, Harrison et al. ${ }^{22}$ 


\section{$\frac{4}{\text { Lee CM, et al. }}$}

Table 2. The prognostic significance of lymph node micrometastasis in patients with gastric cancer

\begin{tabular}{|c|c|c|c|c|}
\hline Study & No. of patients & Comparison of survival (positive : negative) & P-value & Opinions for prognostic significance \\
\hline Maehara et al. ${ }^{5}(1996)$ & $34(\mathrm{pT} 1-4 \mathrm{~N} 0)$ & - & $<0.050$ & Supportive \\
\hline Ishida et al. ${ }^{7}$ (1997) & 109 & - & - & Supportive \\
\hline Kikuch et al. ${ }^{37}$ (1999) & $51(\mathrm{pT} 2-4 \mathrm{~N} 0)$ & - & - & Supportive \\
\hline Harrison et al. ${ }^{22}(2000)$ & $25(\mathrm{pT} 1-4 \mathrm{~N} 0)$ & $35 \%: 66 \% *$ & 0.048 & Supportive \\
\hline Cai et al. ${ }^{13}(2000)$ & 69 (pT1bN0) & $82 \%: 100 \%^{*}$ & $<0.010$ & Supportive \\
\hline Fukagawa et al. $^{49}(2001)$ & $107(\mathrm{pT} 2-3 \mathrm{~N} 0)$ & $94 \%: 89 \% *$ & 0.860 & Contradictory \\
\hline Nakajo et al. $^{24}(2001)$ & $67(\mathrm{pT} 1-3 \mathrm{~N} 0)$ & - & $<0.050$ & Supportive \\
\hline Lee et al..$^{14}(2002)$ & 153 & $49 \%: 76 \% *$ & $<0.001$ & Supportive \\
\hline Yasuda et al. ${ }^{15}(2002)$ & $64(\mathrm{pT} 2-4 \mathrm{aN} 0)$ & $66 \%: 95 \% *$ & $<0.010$ & Supportive \\
\hline Choi et al. ${ }^{12}(2002)$ & 88 (pT1bN0) & $92.9 \%: 95.0 \%^{*}$ & 0.684 & Contradictory \\
\hline Morgagni et al. ${ }^{25}$ (2003) & $300(\mathrm{pT} 1 \mathrm{~N} 0)$ & $94 \%: 89 \%^{*}$ & 0.780 & Contradictory \\
\hline Kim et al. ${ }^{38}(2009)$ & $90(\mathrm{pT} 1 \mathrm{~N} 0)$ & $100 \%: 100 \%^{\dagger}$ & - & Contradictory \\
\hline Cao et al. ${ }^{30}(2011)$ & $160(\mathrm{pT} 1 \mathrm{~N} 0)$ & $55.9 \%: 92.9 \% *$ & $<0.001$ & Supportive \\
\hline Wang et al..$^{50}(2012)$ & $191(\mathrm{pT} 1-3 \mathrm{~N} 0)$ & $27.8 \%: 87.1 \%^{*}$ & $<0.001$ & Supportive \\
\hline Ru et al. ${ }^{10}(2012)$ & 45 (pT1-4N0) & $63.6 \%: 95.6 \%^{\ddagger}$ & 0.011 & Supportive \\
\hline
\end{tabular}

Positive = survival rate of the patients with lymph node micrometastasis; Negative = survival rate of the patients without lymph node micrometastasis; - = none. ${ }^{\star}$ The 5 -year overall survival was compared between two groups. ${ }^{\dagger}$ The disease-free survival rate was compared between two groups. ${ }^{\ddagger}$ The 2-year overall survival rate was compared between two groups.

investigated the 5-year overall survival of patients with pT1-4N0 tumors. In this study, the 5-year overall survival of IHC-positive patients was significantly decreased. Yasuda et al. ${ }^{15}$ also reported the prognostic effect of lymph node micrometastasis in node-negative advanced gastric cancer (AGC). In addition, we reported the significance of lymph node micrometastasis by focusing on its correlation with E-cadherin expression in pT1-3N0 gastric cancer. ${ }^{51}$

On the contrary, several contradictory results have also been reported. According to a report by Fukagawa et al., ${ }^{49}$ the presence of lymph node micrometastasis did not affect the prognosis of 107 patients with pT2-3N0 gastric cancer. In this study, the 10-year as well as 5-year survival were not significantly different between patients with and without lymph node micrometastasis. Morgagni et $\mathrm{al}^{52}$ also reported that 5 - and 10-year overall survival rates were not affected by lymph node micrometastasis in 300 patients with node-negative EGC. Additionally, Choi et al. ${ }^{12}$ reported that lymph node micrometastasis did not influence disease-free survival rate in 88 patients with EGC invading the submucosal layer.

\section{The clinical impact of lymph node micrometa- stasis in early gastric cancer}

Although the prognostic value of lymph node micrometastasis remains debatable in the current field of gastric cancer, lymph node micrometastasis is one of the most interesting topics in EGC. In fact, several studies started from focusing pT1N0 gastric cancer. ${ }^{25,30}$ Moreover, the concept of lymph node micrometastasis affects several types of limited procedures for EGC.

\section{1) Endoscopic resection}

Recently, endoscopic mucosal resection (EMR) was suggested as a substitute for radical gastrectomy, because it has provided the better quality of life as well as favorable long-term outcomes for patients with EGC ${ }^{53}$ In addition, endoscopic submucosal dissection (ESD), a new procedure introduced after EMR, is performed for en bloc resection regardless of the tumor size. ${ }^{54}$ If oncologic safety were definitely guaranteed, there would be no objection to performing EMR or ESD for gastric cancer. However, there are some issues concerning EMR or ESD. One of them is the possibility of lymph node metastasis.

Usually, when lymph node metastasis is not expected, EMR or ESD can be applied. ${ }^{55}$ In other words, conditions in which no lymph node metastasis is expected have been suggested as indications for EMR or ESD. This criterion has been widely accepted in Korea and Japan. ${ }^{55}$ However, the indication of these procedures has been expanded recently, ${ }^{56}$ and this caused some concerns regarding their application. The most important concern is the clinical 
Lymph Node Micrometastasis in Gastric Cancer

detection of lymph node metastasis before EMR or ESD. Although diagnostic tools have been developed considerably, their accuracies remain less than $90 \%$. The most reliable method is pathological examination of the lymph node. ${ }^{57,58}$ Thus, EMR or ESD bears the risk of missing undetected lymph node metastases. Concerning this issue, Jee et al. ${ }^{55}$ reported that $2.8 \%$ of the tumors satisfying the extended indication exhibited lymph node metastasis. These data were obtained via the examinations for macrometastasis. If micrometastasis is considered as regards to this issue, the possibility of missing metastasized lymph nodes is expected to be higher. Therefore, the risk of these procedures should be re-evaluated if the concept of lymph node micrometastasis can be established more clearly.

\section{2) Sentinel node navigation surgery}

Nowadays, a large number of patients with EGC are diagnosed with pNO disease after curative surgery. ${ }^{59}$ These patients are expected to have a promising prognosis without radical lymph node dissection, although radical lymph node dissection should be included in the standard surgery for gastric cancer. ${ }^{4}$ For this reason, endoscopic resection, such as EMR or ESD, has been widely performed in selected patients with EGC. However, the pathologic node status cannot be confirmed in endoscopic resection for gastric cancer. Since all of the cT1N0 cases are not diagnosed as pT1N0, a good prognosis is not guaranteed after endoscopic resection. Therefore, many investigators recently reported the applicability of SNNS in patients with cT1N0 disease. ${ }^{60-63}$ As the pathologic node status is examined intraoperatively, selective lymph node dissection can be performed with oncologic safety.

However, an important concern regarding SNNS is the accuracy of the intraoperative pathologic examination. Recurrence is not acceptable after such limited surgeries, since most patients with cT1N0 disease show promising prognosis after the standard operation including radical lymph node dissection. Therefore, an accurate assessment of intraoperative lymph node status is very critical when performing SNNS.

In general, the intraoperative assessment of lymph node status has been performed using the H\&E staining method during standard surgery. However, considerable discrepancies between the intraoperative and postoperative examination have been demonstrated in the clinical management of patients with gastric cancer. ${ }^{20}$ This issue has also been emphasized in the clinical application of SNNS for patients with malignant melanoma or breast cancer. ${ }^{64,65}$ Intraoperative $\mathrm{H} \& \mathrm{E}$ staining also displayed low sensitivity for detecting lymph node micrometastasis in the patients with breast cancer. ${ }^{64}$
Several strategies have been suggested as solutions for avoiding these issues. First, to overcome the heterogeneous distribution of metastatic foci in lymph nodes, serial sectioning has been proposed. Actually, further examination based on serial sectioning results in the sensitive detection of lymph node micrometastasis in patients with gastric cancer. ${ }^{36}$ Although this method is expensive and laborious in the intraoperative setting, it is one of the important strategies for decreasing the false-negative rate of sentinel lymph node biopsy. ${ }^{66}$ Second, to determine the accurate metastatic status, intraoperative IHC and RT-PCR have been used and developed, as we described previously.

In SNNS, if histological and molecular evaluations do not reveal macro- and micrometastasis in all sentinel lymph nodes that are intraoperatively harvested, the patients could be treated by laparoscopic partial gastrectomy with sentinel node dissection. ${ }^{67-69}$ In addition, even ESD can be applied in such cases. ${ }^{70,71}$ On the other hand, standard gastrectomy with radical lymph node dissection should be performed if macro- or micrometastases are detected in the sentinel nodes. Therefore, the accuracy of detecting micrometastasis is more significant in patients undergoing only limited surgery, because only one micrometastasis should be detected to determine whether it is oncologically safe to leave the lymph nodes that would have been removed during the standard surgery. This is the reason why SNNS is not apart from the studies on lymph node micrometastasis.

\section{The clinical impact of lymph node micrometa- stasis in advanced gastric cancer}

Recently, the most remarkable issue concerning lymph node micrometastasis has been its applicability to limited surgery for EGC. However, lymph node micrometastasis is also associated with some remarkable issues regarding the management of AGC.

\section{1) Stage migration in advanced gastric cancer}

Until the present, many researchers have focused on the detection of lymph node micrometastasis in patients with pNO tumors. The representative reason why they concentrated on node-negative cases was based on the perspective that lymph node macrometastasis would be more significant than lymph node micrometastasis. In other words, the prognostic value of lymph node micrometastasis has been ignored when any macrometastatic node existed. However, while considering the stage migration by lymph node micrometastasis, such negligences could lead to underestimation of the disease state. 


\section{$\frac{6}{\text { Lee CM, et al. }}$}

According to the 7th edition of the American Joint Committee on Cancer system, ${ }^{72}$ the number of metastasized nodes determines the $\mathrm{N}$ stage. If the number of macrometastatic nodes exceeds 15 , this situation indicates the most advanced $\mathrm{N}$ stage according to the current staging system for gastric cancer. Therefore, the detection of lymph node micrometastasis would not affect the $\mathrm{N}$ stage in such conditions. However, if the number of macrometastatic nodes is less than 15 , detection of only one micrometastasis could change the $\mathrm{N}$ stage. Although most previous studies focused on upstaging from $\mathrm{pNO}$, stage migration could occur in the other $\mathrm{N}$ stages, namely, pN1, pN2, pN3a, and pN3b.

These $\mathrm{N}$ stages account for a considerable proportion of patients with AGC. Moreover, as the appropriate application of chemotherapeutic agents has improved the prognosis of patients with advanced disease, ${ }^{73-75}$ changing the adjuvant treatment according to stage migration is more critical in AGC than in EGC.

\section{2) The new staging system}

Another significant issue regarding lymph node micrometastasis in AGC is the node staging system. The current staging system states that lymph node micrometastases have the same prognostic value as lymph node macrometastases. ${ }^{19}$ However, as described above, the prognostic value of lymph node micrometastasis remains controversial, since some results are supportive and other results are

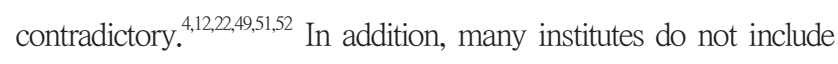
lymph node micrometastasis in the staging. Concerning this issue, we recently reported the validity of including micrometastasis in the node staging. ${ }^{76}$ In this study, a new staging system including lymph node micrometastasis was suggested, and it was also compared to the conventional staging system, in which only the number of macrometastatic nodes was reflected. As a result, the prognostic difference between the N2 and N3a stages became more distinct in the new staging system than in the conventional staging system. ${ }^{76}$ Although this result cannot be generalized to all clinical conditions, it implies that lymph node micrometastasis could affect the stage in patients with AGC as well as in patients with EGC.

\section{Conclusions}

Through the efforts of many previous researchers, the clinical significance of lymph node micrometastasis has been accepted in the field of gastric cancer. Although there is no consensus, the studies on lymph node micrometastasis are evolving to overcome the contradictory results and extend the scope of its application from EGC to AGC.

\section{References}

1. Siewert JR, Böttcher K, Stein HJ, Roder JD. Relevant prognostic factors in gastric cancer: ten-year results of the German Gastric Cancer Study. Ann Surg 1998;228:449-461.

2. Nitti D, Marchet A, Olivieri M, Ambrosi A, Mencarelli R, Belluco $C$, et al. Ratio between metastatic and examined lymph nodes is an independent prognostic factor after D2 resection for gastric cancer: analysis of a large European monoinstitutional experience. Ann Surg Oncol 2003;10:1077-1085.

3. Kwon SJ, Kim GS. Prognostic significance of lymph node metastasis in advanced carcinoma of the stomach. Br J Surg 1996;83:1600-1603.

4. Maehara Y, Okuyama T, Moriguchi S, Orita H, Kusumoto $\mathrm{H}$, Korenaga D, et al. Prophylactic lymph node dissection in patients with advanced gastric cancer promotes increased survival time. Cancer 1992;70:392-395.

5. Maehara Y, Oshiro T, Endo K, Baba H, Oda S, Ichiyoshi Y, et al. Clinical significance of occult micrometastasis lymph nodes from patients with early gastric cancer who died of recurrence. Surgery 1996;119:397-402.

6. Siewert JR, Kestlmeier R, Busch R, Böttcher K, Roder JD, Müller J, et al. Benefits of D2 lymph node dissection for patients with gastric cancer and $\mathrm{pN} 0$ and $\mathrm{pN} 1$ lymph node metastases. Br J Surg 1996;83:1144-1147.

7. Ishida K, Katsuyama T, Sugiyama A, Kawasaki S. Immunohistochemical evaluation of lymph node micrometastases from gastric carcinomas. Cancer 1997;79:1069-1076.

8. Deng J, Liang H, Sun D, Zhang R, Zhan H, Wang X. Prognosis of gastric cancer patients with node-negative metastasis following curative resection: outcomes of the survival and recurrence. Can J Gastroenterol 2008;22:835-839.

9. Saito H, Kuroda H, Matsunaga T, Fukuda K, Tatebe S, Tsujitani $S$, et al. Prognostic indicators in node-negative advanced gastric cancer patients. J Surg Oncol 2010;101:622-625.

10. Ru Y, Zhang L, Chen Q, Gao SG, Wang GP, Qu ZF, et al. Detection and clinical significance of lymph node micrometastasis in gastric cardia adenocarcinoma. J Int Med Res 2012;40:293299.

11. Yonemura Y, Endo Y, Hayashi I, Kawamura T, Yun HY, Bandou E. Proliferative activity of micrometastases in the lymph nodes of patients with gastric cancer. Br J Surg 2007;94:731- 


\section{$\frac{7}{\text { Lymph Node Micrometastasis in Gastric Cancer }}$}

736.

12. Choi HJ, Kim YK, Kim YH, Kim SS, Hong SH. Occurrence and prognostic implications of micrometastases in lymph nodes from patients with submucosal gastric carcinoma. Ann Surg Oncol 2002;9:13-19.

13. Cai J, Ikeguchi M, Maeta M, Kaibara N. Micrometastasis in lymph nodes and microinvasion of the muscularis propria in primary lesions of submucosal gastric cancer. Surgery 2000;127:32-39.

14. Lee E, Chae Y, Kim I, Choi J, Yeom B, Leong AS. Prognostic relevance of immunohistochemically detected lymph node micrometastasis in patients with gastric carcinoma. Cancer 2002;94:2867-2873.

15. Yasuda K, Adachi Y, Shiraishi N, Inomata M, Takeuchi H, Kitano S. Prognostic effect of lymph node micrometastasis in patients with histologically node-negative gastric cancer. Ann Surg Oncol 2002;9:771-774.

16. Hata M, Machi J, Mamou J, Yanagihara ET, Saegusa-Beecroft E, Kobayashi GK, et al. Entire-volume serial histological examination for detection of micrometastases in lymph nodes of colorectal cancers. Pathol Oncol Res 2011;17:835-841.

17. Matsumoto M, Natsugoe S, Ishigami S, Nakashima S, Nakajo A, Miyazono F, et al. Lymph node micrometastasis and lymphatic mapping determined by reverse transcriptasepolymerase chain reaction in pN0 gastric carcinoma. Surgery 2002;131:630-635.

18. Sobin LH, Wittekind C, International Union against Cancer. TNM classification of malignant tumours. 6th ed. New York: Wiley-Liss, 2002:xxiii, 239.

19. Sobin LH, Gospodarowicz MK, Wittekind C, International Union against Cancer. TNM classification of malignant tumours. 7th ed. Chichester, West Sussex, UK; Hoboken, NJ: Wiley-Blackwell, 2010:xx, 309.

20. Arigami T, Uenosono Y, Yanagita S, Nakajo A, Ishigami S, Okumura $\mathrm{H}$, et al. Clinical significance of lymph node micrometastasis in gastric cancer. Ann Surg Oncol 2013;20:515-521.

21. Kashimura H, Ajioka Y, Watanabe H, Nishikura K, Iiri T, Asakura H. Risk factors for nodal micrometastasis of submucosal gastric carcinoma: assessment of indications for endoscopic treatment. Gastric Cancer 1999;2:33-39.

22. Harrison LE, Choe JK, Goldstein M, Meridian A, Kim SH, Clarke K. Prognostic significance of immunohistochemical micrometastases in node negative gastric cancer patients. J Surg Oncol 2000;73:153-157.
23. Okada Y, Fujiwara Y, Yamamoto H, Sugita Y, Yasuda T, Doki $\mathrm{Y}$, et al. Genetic detection of lymph node micrometastases in patients with gastric carcinoma by multiple-marker reverse transcriptase-polymerase chain reaction assay. Cancer 2001;92:2056-2064.

24. Nakajo A, Natsugoe S, Ishigami S, Matsumoto M, Nakashima S, Hokita $S$, et al. Detection and prediction of micrometastasis in the lymph nodes of patients with pN0 gastric cancer. Ann Surg Oncol 2001;8:158-162.

25. Morgagni P, Saragoni L, Scarpi E, Zattini PS, Zaccaroni A, Morgagni D, et al. Lymph node micrometastases in early gastric cancer and their impact on prognosis. World J Surg 2003;27:558-561.

26. Arigami T, Natsugoe S, Uenosono Y, Arima H, Mataki Y, Ehi $\mathrm{K}$, et al. Lymphatic invasion using D2-40 monoclonal antibody and its relationship to lymph node micrometastasis in $\mathrm{pN} 0$ gastric cancer. Br J Cancer 2005;93:688-693.

27. Sonoda H, Yamamoto K, Kushima R, Yamamoto H, Naitoh $\mathrm{H}$, Okabe $\mathrm{H}$, et al. Detection of lymph node micrometastasis in pN0 early gastric cancer: efficacy of duplex RT-PCR with MUC2 and TFF1 in mucosal cancer. Oncol Rep 2006;16:411416.

28. Wu ZY, Li JH, Zhan WH, He YL, Wan J. Effect of lymph node micrometastases on prognosis of gastric carcinoma. World J Gastroenterol 2007;13:4122-4125.

29. Ishii K, Kinami S, Funaki K, Fujita H, Ninomiya I, Fushida S, et al. Detection of sentinel and non-sentinel lymph node micrometastases by complete serial sectioning and immunohistochemical analysis for gastric cancer. J Exp Clin Cancer Res 2008;27:7.

30. Cao L, Hu X, Zhang Y, Huang G. Adverse prognosis of clustered-cell versus single-cell micrometastases in pN0 early gastric cancer. J Surg Oncol 2011;103:53-56.

31. Moll R, Franke WW, Schiller DL, Geiger B, Krepler R. The catalog of human cytokeratins: patterns of expression in normal epithelia, tumors and cultured cells. Cell 1982;31:11-24.

32. Yamamoto N, Kato Y, Yanagisawa A, Ohta H, Takahashi T, Kitagawa T. Predictive value of genetic diagnosis for cancer micrometastasis: histologic and experimental appraisal. Cancer 1997;80:1393-1398.

33. Shiraishi N, Sato K, Yasuda K, Inomata M, Kitano S. Multivariate prognostic study on large gastric cancer. J Surg Oncol 2007;96:14-18.

34. Al-Moundhri MS, Al-Bahrani B, Burney IA, Nirmala V, Al- 


\section{$\frac{8}{\text { Lee CM, et al. }}$}

Madhani A, Al-Mawaly K, et al. The prognostic determinants of gastric cancer treatment outcome in Omani Arab patients. Oncology 2006;70:90-96.

35. Dicken BJ, Saunders LD, Jhangri GS, de Gara C, Cass C, Andrews S, et al. Gastric cancer: establishing predictors of biologic behavior with use of population-based data. Ann Surg Oncol 2004;11:629-635.

36. Isozaki H, Okajima K, Fujii K. Histological evaluation of lymph node metastasis on serial sectioning in gastric cancer with radical lymphadenectomy. Hepatogastroenterology 1997;44:11331136.

37. Kikuchi Y, Tsuchiya A, Ando Y, Yoshida T, Takenosita S. Immunohistochemical detection of lymph node microinvolvement in node-negative gastric cancer. Gastric Cancer 1999;2:173-178.

38. Kim JJ, Song KY, Hur H, Hur JI, Park SM, Park CH. Lymph node micrometastasis in node negative early gastric cancer. Eur J Surg Oncol 2009;35:409-414.

39. Bostick PJ, Morton DL, Turner RR, Huynh KT, Wang HJ, Elashoff R, et al. Prognostic significance of occult metastases detected by sentinel lymphadenectomy and reverse transcriptasepolymerase chain reaction in early-stage melanoma patients. J Clin Oncol 1999;17:3238-3244.

40. Bostick PJ, Huynh KT, Sarantou T, Turner RR, Qi K, Giuliano AE, et al. Detection of metastases in sentinel lymph nodes of breast cancer patients by multiple-marker RT-PCR. Int J Cancer 1998;79:645-651.

41. Hoon DS, Bostick P, Kuo C, Okamoto T, Wang HJ, Elashoff $\mathrm{R}$, et al. Molecular markers in blood as surrogate prognostic indicators of melanoma recurrence. Cancer Res 2000;60:22532257.

42. Gerhard M, Juhl H, Kalthoff H, Schreiber HW, Wagener C, Neumaier M. Specific detection of carcinoembryonic antigenexpressing tumor cells in bone marrow aspirates by polymerase chain reaction. J Clin Oncol 1994;12:725-729.

43. Kubota K, Nakanishi H, Hiki N, Shimizu N, Tsuji E, Yamaguchi $\mathrm{H}$, et al. Quantitative detection of micrometastases in the lymph nodes of gastric cancer patients with real-time RT-PCR: a comparative study with immunohistochemistry. Int J Cancer 2003;105:136-143.

44. Ruud P, Fodstad O, Hovig E. Identification of a novel cytokeratin 19 pseudogene that may interfere with reverse transcriptase-polymerase chain reaction assays used to detect micrometastatic tumor cells. Int J Cancer 1999;80:119-125.
45. Kuo CT, Hoon DS, Takeuchi H, Turner R, Wang HJ, Morton $\mathrm{DL}$, et al. Prediction of disease outcome in melanoma patients by molecular analysis of paraffin-embedded sentinel lymph nodes. J Clin Oncol 2003;21:3566-3572.

46. Yaguchi Y, Sugasawa H, Tsujimoto H, Takata H, Nakabayashi $\mathrm{K}$, Ichikura T, et al. One-step nucleic acid amplification (OSNA) for the application of sentinel node concept in gastric cancer. Ann Surg Oncol 2011;18:2289-2296.

47. Tsujimoto M, Nakabayashi K, Yoshidome K, Kaneko T, Iwase T, Akiyama F, et al. One-step nucleic acid amplification for intraoperative detection of lymph node metastasis in breast cancer patients. Clin Cancer Res 2007;13:4807-4816.

48. Yanagita S, Natsugoe S, Uenosono Y, Arigami T, Funasako Y, Hirata $M$, et al. The utility of rapid diagnosis of lymph node metastasis in gastric cancer using a multiplex real-time reverse transcription polymerase chain reaction assay. Oncology 2009;77:205-211.

49. Fukagawa T, Sasako M, Mann GB, Sano T, Katai H, Maruyama $\mathrm{K}$, et al. Immunohistochemically detected micrometastases of the lymph nodes in patients with gastric carcinoma. Cancer 2001;92:753-760.

50. Wang J, Yu JC, Kang WM, Wang WZ, Liu YQ, Gu P. The predictive effect of cadherin-17 on lymph node micrometastasis in pN0 gastric cancer. Ann Surg Oncol 2012;19:1529-1534.

51. Kim JH, Park JM, Jung CW, Park SS, Kim SJ, Mok YJ, et al. The significances of lymph node micrometastasis and its correlation with E-cadherin expression in pT1-T3N0 gastric adenocarcinoma. J Surg Oncol 2008;97:125-130.

52. Morgagni P, Saragoni L, Folli S, Gaudio M, Scarpi E, Bazzocchi F, et al. Lymph node micrometastases in patients with early gastric cancer: experience with 139 patients. Ann Surg Oncol 2001;8:170-174.

53. Ono H, Kondo H, Gotoda T, Shirao K, Yamaguchi H, Saito D, et al. Endoscopic mucosal resection for treatment of early gastric cancer. Gut 2001;48:225-229.

54. Hotta K, Oyama T, Akamatsu T, Tomori A, Hasebe O, Nakamura $\mathrm{N}$, et al. A comparison of outcomes of endoscopic submucosal dissection (ESD) For early gastric neoplasms between high-volume and low-volume centers: multi-center retrospective questionnaire study conducted by the Nagano ESD Study Group. Intern Med 2010;49:253-259.

55. Jee YS, Hwang SH, Rao J, Park DJ, Kim HH, Lee HJ, et al. Safety of extended endoscopic mucosal resection and endoscopic submucosal dissection following the Japanese Gastric Cancer 


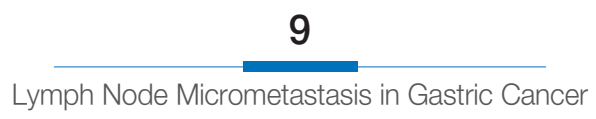

Association treatment guidelines. Br J Surg 2009;96:1157-1161.

56. Yamaguchi N, Isomoto H, Fukuda E, Ikeda K, Nishiyama H, Akiyama M, et al. Clinical outcomes of endoscopic submucosal dissection for early gastric cancer by indication criteria. Digestion 2009;80:173-181.

57. Rösch T. Endosonographic staging of gastric cancer: a review of literature results. Gastrointest Endosc Clin N Am 1995;5:549-557.

58. Polkowski M, Palucki J, Wronska E, Szawlowski A, Nasierowska-Guttmejer A, Butruk E. Endosonography versus helical computed tomography for locoregional staging of gastric cancer. Endoscopy 2004;36:617-623.

59. Sano T, Hollowood A. Early gastric cancer: diagnosis and less invasive treatments. Scand J Surg 2006;95:249-255.

60. Aikou T, Higashi H, Natsugoe S, Hokita S, Baba M, Tako S. Can sentinel node navigation surgery reduce the extent of lymph node dissection in gastric cancer? Ann Surg Oncol 2001;8:90S-93S.

61. Kitagawa Y, Fujii H, Mukai M, Kubota T, Otani Y, Kitajima M. Radio-guided sentinel node detection for gastric cancer. Br J Surg 2002;89:604-608.

62. Arigami T, Natsugoe S, Uenosono Y, Mataki Y, Ehi K, Higashi $\mathrm{H}$, et al. Evaluation of sentinel node concept in gastric cancer based on lymph node micrometastasis determined by reverse transcription-polymerase chain reaction. Ann Surg 2006;243:341-347.

63. Tajima Y, Yamazaki K, Masuda Y, Kato M, Yasuda D, Aoki T, et al. Sentinel node mapping guided by indocyanine green fluorescence imaging in gastric cancer. Ann Surg 2009;249:58-62.

64. Chao C, Wong SL, Ackermann D, Simpson D, Carter MB, Brown CM, et al. Utility of intraoperative frozen section analysis of sentinel lymph nodes in breast cancer. Am J Surg 2001;182:609-615.

65. Tanis PJ, Boom RP, Koops HS, Faneyte IF, Peterse JL, Nieweg $\mathrm{OE}$, et al. Frozen section investigation of the sentinel node in malignant melanoma and breast cancer. Ann Surg Oncol 2001;8:222-226.
66. Lee HS, Lee HE, Park do J, Park YS, Kim HH. Precise pathologic examination decreases the false-negative rate of sentinel lymph node biopsy in gastric cancer. Ann Surg Oncol 2012;19:772-778.

67. Saikawa Y, Otani Y, Kitagawa Y, Yoshida M, Wada N, Kubota T, et al. Interim results of sentinel node biopsy during laparoscopic gastrectomy: possible role in function-preserving surgery for early cancer. World J Surg 2006;30:1962-1968.

68. Takeuchi H, Kitagawa Y. New sentinel node mapping technologies for early gastric cancer. Ann Surg Oncol 2013;20:522532.

69. Takeuchi H, Oyama T, Kamiya S, Nakamura R, Takahashi T, Wada N, et al. Laparoscopy-assisted proximal gastrectomy with sentinel node mapping for early gastric cancer. World J Surg 2011;35:2463-2471.

70. Bok GH, Kim YJ, Jin SY, Chun CG, Lee TH, Kim HG, et al. Endoscopic submucosal dissection with sentinel node navigation surgery for early gastric cancer. Endoscopy 2012;44:953956.

71. Takeuchi H, Kitagawa Y. Sentinel node navigation surgery in patients with early gastric cancer. Dig Surg 2013;30:104-111.

72. Washington K. 7th edition of the AJCC cancer staging manual: stomach. Ann Surg Oncol 2010;17:3077-3079.

73. Hirata K, Horikoshi N, Aiba K, Okazaki M, Denno R, Sasaki $\mathrm{K}$, et al. Pharmacokinetic study of S-1, a novel oral fluorouracil antitumor drug. Clin Cancer Res 1999;5:2000-2005.

74. Ohtsu A. Current status and future prospects of chemotherapy for metastatic gastric cancer: a review. Gastric Cancer 2005;8:95-102.

75. Koizumi W, Narahara H, Hara T, Takagane A, Akiya T, Takagi $\mathrm{M}$, et al. S-1 plus cisplatin versus S-1 alone for first-line treatment of advanced gastric cancer (SPIRITS trial): a phase III trial. Lancet Oncol 2008;9:215-221.

76. Lee CM, Cho JM, Jang YJ, Park SS, Park SH, Kim SJ, et al. Should lymph node micrometastasis be considered in node staging for gastric cancer?: the significance of lymph node micrometastasis in gastric cancer. Ann Surg Oncol 2014 [Epub]. 